\title{
ANALISIS PERILAKU KONSUMEN DAN KEAMANAN KARTU KREDIT PERBANKAN
}

\author{
Decky Hendarsyah \\ Sekolah Tinggi Ilmu Ekonomi (STIE) Syariah Bengkalis \\ deckydb@gmail.com
}

\begin{abstract}
This paper discusses consumer behavior and banking credit card security. Credit cards are present as one of the non-cash payment methods that simplify business and financial matters so that many consumers use them. After review and discussion, it was found that consumer behavior in using credit cards is more dominated by personal factors. With the drive for needs and lifestyle, many consumers are interested in using a credit card. The bank as a credit card issuer also provides sophisticated and multi-layered security features. Even so, it still has a gap for the presence of fraud crime in various ways and forms. In order for credit cards to be safe from crime and fraud, consumer behavior must be changed by maintaining confidentiality, caution and vigilance in conducting transactions.
\end{abstract}

Keywords: Consumer Behavior, Security, Credit Cards, Banking.

\begin{abstract}
ABSTRAK
Tulisan ini membahas tentang perilaku konsumen dan keamanan kartu kredit perbankan. Kartu kredit hadir sebagai salah satu metode pembayaran non tunai yang mempermudah urusan bisnis dan keuangan sehingga banyak konsumen yang menggunakannya. Setelah dikaji dan dilakukan pembahasan maka didapat bahwa perilaku konsumen dalam menggunakan kartu kredit lebih didominasi oleh faktor pribadi. Dengan adanya dorongan kebutuhan dan gaya hidup maka banyak konsumen tertarik menggunakan kartu kredit. Pihak perbankan selaku penerbit kartu kredit juga menyediakan fitur keamanan yang canggih dan berlapis. Walaupun begitu tetap memiliki celah untuk hadirnya kejahatan penipuan dengan cara dan bentuk yang bermacam-macam. Agar kartu kredit aman dari kejahatan dan penipuan, maka perilaku konsumen harus dirubah dengan cara menjaga kerahasiaan, kehati-hatian dan kewaspadaan dalam melakukan transaksi.
\end{abstract}

Kata kunci: Perilaku Konsumen, Keamanan, Kartu Kredit, Perbankan.

\section{PENDAHULUAN}

Perkembangan ekonomi yang begitu pesat menuntut terjadinya transaksi keuangan setiap saat sehingga pembayaran tunai dinilai telah ketinggalan zaman. Apalagi dengan hadirnya sarana jual beli dan transaksi online saat ini menghadirkan perilaku konsumen dan bisnis yang serba praktis dan instan. Oleh sebab itu bermunculan berbagai macam metode pembayaran transaksi keuangan non tunai salah satunya yang menjadi pilihan adalah kartu kredit. Kartu kredit saat ini dianggap sebagai salah satu bagian dari gaya hidup masyarakat modern. 
Dari data yang dirilis oleh Bank Indonesia sampai akhir tahun 2018, bahwa penggunaan kartu kredit dalam transaksi keuangan non tunai menduduki peringkat ketiga setelah uang elektronik dan kartu debit (Fitra 2019). Menurut data dari AKKI (2020) bahwa jumlah kartu kredit yang beredar di Indonesia dari tahun 2009 sampai 2019 meningkat dengan signifikan, tahun 2009 kartu kredit yang beredar di Indonesia sebanyak 12.259.295, tahun 2019 menjadi 17.487.057.

Kemudian menurut data dari Bank Indonesia (2019) bahwa total volume transaksi kartu kredit tahun 2019 mencapai 319.535.688 transaksi dengan nilai 314 triliyun rupiah. Walaupun kartu kredit tidak sepopuler uang elektronik, tapi kartu kredit hadir sebagai salah satu metode pembayaran yang mempermudah urusan bisnis dan keuangan. Sehingga pihak perbankan sangat gencar dalam memasarkan kartu kredit kepada konsumen dengan fasilitas yang menggiurkan. Penggunaan kartu kredit memerlukan tingkat kepercayaan yang tinggi dari penggunanya. Banyak kemudahan dan potongan yang diberikan oleh pihak perbankan. Namun terdapat masalah kredibilitas yang menjadi unsur terpenting dalam penggunaan kartu kredit oleh konsumen. Oleh sebab itu pihak perbankan harus melakukan pengawasan dan pemantauan yang ketat terhadap pengguna kartu kredit.

Ditengah pesatnya perkembangan teknologi menjaga data pribadi yang seharusnya rahasia, menjadi semakin sulit akibat praktek jual beli data pribadi (Kresna 2019). Tersebarnya data pribadi seakan memberi salah satu jalan atau angin segar bagi para pelaku kejahatan untuk melakukan aksi penipuan menggunakan sarana kartu kredit. Sebagai alat transaksi non tunai keamanan kartu kredit memiliki celah untuk hadirnya kejahatan penipuan, walaupun terlihat sepele modus penipuan kartu kredit tidak disadari oleh penggunanya. Dengan adanya teknologi keamanan kartu kredit tidak menghalangi pelaku kejahatan untuk melakukan aksinya, kemudian aksi tersebut juga terpicu dengan adanya dorongan dari perilaku konsumen dalam menggunakan kartu kredit. Untuk itu penulis bertujuan untuk membahas mengenai perilaku konsumen dan keamanan kartu kredit perbankan.

\section{TELAAH LITERATUR}

\section{Perilaku Konsumen}

Menurut Mowen dan Michael (1998) bahwa perilaku konsumen merupakan aktivitas ketika seseorang mendapatkan, mengkonsumsi atau membuang barang atau jasa pada saat proses pembelian. Sedangkan menurut Engel et al. (2004) perilaku konsumen adalah tindakan-tindakan produk dan jasa, termasuk didalamnya proses keputusan yang mengawali serta mengikuti tindakan pembelian tersebut, dimana tindakan tersebut terlibat secara langsung dalam proses memperoleh, mengkonsumsi bahkan membuang atau tidak jadi menggunakan suatu produk atau jasa.

Senada dengan Engel et al., Setiadi (2013) berpendapat bahwa perilaku konsumen adalah tindakan yang langsung terlibat dalam mendapatkan, mengkonsumsi dan menghabiskan produk atau jasa, termasuk proses keputusan yang mendahului dan menyusuli tindakan tersebut. Menurut pendapat Firmansyah (2018) bahwa perilaku konsumen merupakan suatu proses pengambilan keputusan oleh konsumen dalam memilih, membeli, memakai serta memanfaatkan produk, 
jasa, serta gagasan atau pengalaman dalam rangka memuaskan kebutuhan dan hasrat konsumen.

Faktor yang mempengaruhi perilaku konsumen adalah kebudayaan (seperti: kultur, sub kultur dan kelas sosial), sosial (seperti: kelompok, keluarga, peran dan status), pribadi (seperti: umur, tahap daur hidup, pekerjaan, keadaan ekonomi, gaya hidup, kepribadian dan konsep diri), psikologis (seperti: motivasi, persepsi, proses belajar, kepercayaan dan sikap) (Simamora 2004, 6; Setiadi 2013). Dalam situasi yang spesifik atau pengaruh situasi menjelaskan tentang suatu kondisi ketika seorang konsumen ingin menentukan keputusan pembelian. Dalam situasi tersebut, terdapat lima prinsip yang membentuk pengaruh situasi yaitu: (a) physical, merupakan karakteristik lokasi di saat pembeli ingin melakukan keputusan pembelian. (b) Social, merupakan interaksi yang terjadi ketika menentukan keputusan pembelian. (c) Time, waktu yang tersedia ketika melakukan pembelian. (d) Motivational, alasan untuk melakukan pembelian. (e) Mood, emosi sesorang ketika akan melakukan keputusan pembelian (Prisgunanto 2017).

Ciri-ciri perilaku konsumen ada yang bersifat rasional dan irasional. Ciriciri perilaku konsumen yang bersifat rasional yaitu: (a) konsumen memilih produk sesuai kebutuhan dan keinginannya, (b) produk yang dipilih konsumen memberikan manfaat yang optimal bagi konsumen, (c) konsumen memilih produk yang kualitasnya bagus, (d) konsumen memilih produk yang harganya sesuai dengan kemampuan dan pendapatan konsumen, (e) konsumen memilih produk sesuai dengan kenyamanan lingkungan tempat transaksi. Ciri-ciri perilaku konsumen yang bersifat irasional yaitu: (a) konsumen sangat cepat tertarik dengan iklan dan promosi di media. (b) konsumen memilih produk bermerek terkenal, (c) konsumen memilih produk bukan untuk kebutuhan tetapi untuk gengsi, (d) konsumen memilih produk hanya karena ingin mencoba-coba (Firmansyah 2018).

\section{Konsep Keamanan}

Keamanan merupakan sebagai kondisi atau kualitas yang bebas dari ketakutan, kecemasan, atau kepedulian (Hendarsyah 2012; Miftahuddin dan Decky 2019). Terdapat tiga komponen dasar sebagai pertimbangan dalam perancangan dan pembahasan sistem keamanan diantaranya: (a) Confidentiality adalah penyembunyian informasi atau sumber daya yang berkaitan dengan pencegahan akan pengaksesan terhadap informasi atau sumber daya yang dilakukan oleh pihak yang tidak berhak. (b) Integrity merupakan keandalan data atau sumber daya dan biasanya dirumuskan untuk mencegah perubahan yang tidak sah. Integritas mencakup integritas data (isi dari informasi) dan integritas asli (sumber data, sering disebut otentikasi). Dengan demikian integrity berkaitan dengan pencegahan modifikasi informasi yang dilakukan oleh pihak yang tidak berhak. (c) Availability merupakan kemampuan untuk menggunakan informasi atau sumber daya yang diinginkan. Availability adalah aspek yang penting dalam mendesain sistem karena suatu sistem yang tidak memiliki availability sama buruknya dengan tidak ada sistem sama sekali. Availability dapat melakukan pencegahan akan penguasaan informasi atau sumber daya oleh pihak yang tidak berhak (Bishop 2004; Hendarsyah dan Retantyo 2011). 


\section{Kartu Kredit}

Menurut Suryohadibroto dan Prakoso, kartu kredit adalah alat pembayaran sebagai pengganti uang tunai yang sewaktu-waktu dapat digunakan konsumen untuk ditukarkan dengan produk barang dan jasa yang diinginkannya pada tempat-tempat yang menerima kartu kredit (merchant) atau bisa digunakan konsumen untuk menguangkan kepada bank penerbit atau jaringannya (cash advance), dalam (Hermansyah 2011; Dhirima et al. 2019). Kartu Kredit merupakan salah satu alat pembayaran dengan menggunakan kartu (APMK). Kartu kredit menawarkan dua fungsi yang berbeda kepada konsumen yaitu sebagai alat pembayaran dan sumber kredit (Canner dan Luckett 1992) dalam (Abdelrahman 2011; Lestari et al. 2017).

Sedangkan menurut Bank Indonesia (2020) bahwa kartu kredit adalah Alat Pembayaran Menggunakan Kartu (APMK) yang dapat digunakan untuk melakukan pembayaran atas kewajiban yang timbul dari suatu kegiatan ekonomi, termasuk transaksi pembelanjaan dan/atau untuk melakukan penarikan tunai, dimana kewajiban pembayaran pemegang kartu dipenuhi terlebih dahulu oleh acquirer atau penerbit, dan pemegang kartu berkewajiban untuk melakukan pembayaran pada waktu yang disepakati baik dengan pelunasan secara sekaligus (charge card) ataupun dengan pembayaran secara angsuran.

Kartu kredit dapat digolongkan menjadi dua yaitu kartu kredit konvensional dan kartu kredit syariah (Yusuf 2011; Dhirima et al. 2019). Persamaan antara kartu kredit konvensional dengan kartu kredit syariah adalah (a) sebagai alat pembayaran, (b) memiliki biaya tahunan, biaya keterlambatan dan biaya lain seperti biaya materai, (c) pihak-pihak yang terkait dengan penerbitan dan penggunaan kartu sama, (d) prosedur transaksi dalam mekanisme pembayaran melibatkan tiga pihak yaitu bank penerbit (issuer bank), pemegang kartu (card holder) dan pedagang (merchant) (Zuhra 2017).

Perbedaan kartu kredit konvensional dengan kartu kredit syariah yaitu: (a) Skema perjanjian, kartu kredit syariah didukung oleh tiga jenis skema perjanjian yang menjadi dasar kesyariahannya yaitu: penjaminan atas transaksi dengan merchant, pinjaman dana atas fasilitas penarikan uang tunai dan sewa atas jasa sistem pembayaran dan pelayanan. Sedangkan pada sistem kartu kredit konvensional kredit diberikan atas akad pinjaman dan nasabah diharuskan mengembalikan pinjaman bersama bunga. Nantinya dari skema yang dipilih oleh nasabah, bank syariah penerbit kartu mengenakan biaya kepada pemegang kartu. (b) Penerapan bunga, kartu kredit konvensional dikenakan bunga, sedangkan kartu kredit syariah tidak dikenakan bunga melainkan dengan ketentuan sebagai berikut: dikenakan iuran keanggotaan bulanan dan adanya batasan yang telah ditetapkan oleh MUI. (c) Penerapan fee, kartu kredit konvensional diterapkan sistem bunga, kartu kredit syariah diterapkan fee penarikan uang tunai. Penerbit kartu boleh menerima fee penarikan uang tunai (rusum sahb al-nuqûd) sebagai fee atas pelayanan dan penggunaan fasilitas yang besarnya tidak dikaitkan dengan jumlah penarikan. Untuk fasilitas transaksi dengan merchant, besarnya biaya didasarkan pada nilai transaksi sehingga bersifat fluktuatif. Meskipun komponen fee banyak, namun dari sisi nominal, fee yang dikenakan oleh kartu kredit syariah lebih rendah dibandingkan suku bunga yang dikenakan pada kartu kredit konvensional. (d) Penerapan denda, untuk melatih nasabah lebih disiplin melunasi utang yang terjadi sesuai dengan transaksi. Terdapat dua jenis denda yang akan 
dikenakan yaitu ta'widh, sebagai biaya penagihan bank per bulan dan $3 \%$ dari tagihan. Tetapi denda tersebut bukanlah bunga seperti pada kartu kredit konvensional, itu merupakan qardhul hasan yang akan disumbangkan ke BAZIS. Dari hasi denda tersebut bank tidak akan mengambil keuntungan karena akan disalurkan untuk kebutuhan sosial. (e) Sistem tarik tunai ATM, kartu kredit konvensional ketika melakukan tarik tunai akan dikenakan biaya penarikan sebesar 4-10\% dari total nominal yang ditarik. Kartu kredit syariah untuk penarikan tunai di ATM hanya dikenakan biaya penarikan. Biaya monthly fee untuk cash advance sama besarannya dengan biaya monthly fee untuk retail/belanja yaitu sama dengan 2,95\% (Yusuf 2011; Astari 2016; Zuhra 2017).

Kartu kredit selain digunakan sebagai alat pembayaran juga bermanfaat untuk pinjaman murah, untuk berbelanja online, dalam transaksi online dapat dibatalkan dengan mudah, pengeluaran tercatat, banyak potongan ketika berbelanja, traveling menjadi lebih murah, akomodasi lebih hemat, bisa dijadikan mata uang internasional, praktis dan aman, bisa digunakan untuk mengajukan kredit tanpa agunan (Tokopedia 2019).

\section{PEMBAHASAN}

\section{Perilaku Konsumen Kartu Kredit}

Perilaku konsumen dipengaruhi oleh faktor kebudayaan, sosial, pribadi dan psikologi. Kristianti (2014) menyatakan bahwa perilaku konsumen masyarakat Indonesia yang masih sangat mengikuti trend bukan pada kebutuhan, lebih melihat kemasan yang menarik, lebih karena dorongan kelompok sosial dan merupakan konsumen instan, maka keberadaan kartu kredit menjadi pemicu meningkatnya perilaku konsumtif konsumen di Indonesia. Margaretha dan Siti (2015) menyatakan bahwa usia, tingkat pendidikan dan pendapatan mempengaruhi konsumen dalam menggunakan kartu kredit, dimana usia, tingkat pendidikan dan pendapatan masuk kedalam faktor pribadi. Astuti dan Nurlaely (2017) menyatakan bahwa faktor kepribadian dan psikologis yang mempengaruhi konsumen dalam menggunakan kartu kredit, tetapi yang lebih kuat pengaruhnya adalah kepribadian dibandingkan dengan psikologis sedangkan faktor kebudayaan dan sosial tidak berpengaruh secara signifikan.

Fauzan (2017) menyatakan bahwa gaya hidup konsumen sangat mempengaruhi dalam penggunaan kartu kredit, dimana gaya hidup merupakan bagian dari faktor pribadi. Lestari et al. (2017) menyatakan bahwa sikap, norma subjektif dan presepsi mempengaruhi konsumen dalam menggunakan kartu kredit, dimana sikap dan presepsi masuk kedalam faktor psikologi, sedangkan norma subjektif masuk kedalam faktor sosial. Ismail (2018) menyatakan bahwa kebudayaan, sosial, pribadi, psikologis, achievement, power dan affiliation menjadi faktor yang mempengaruhi konsumen dalam menggunakan kartu kredit, tetapi dari ketujuh faktor tersebut yang lebih dominan adalah faktor achievement, power dan pribadi. Jadi dari beberapa hasil penelitian tersebut dapat dikatakan bahwa perilaku konsumen dalam menggunakan kartu kredit lebih didominasi oleh faktor pribadi. 


\section{Keamanan Kartu Kredit}

Kartu kredit merupakan salah satu alat pembayaran non tunai yang digunakan nasabah perbankan dalam bertransaksi. Keamanan kartu kredit sangat penting diperhatikan ketika berniat untuk menggunakan kartu kredit. Perbankan sendiri sebagai pihak yang menerbitkan kartu kredit sudah memberikan berbagai macam teknologi dan keamanan berlapis dalam mengamankan kartu kredit nasabah. Teknologi keamanan kartu kredit dapat berupa chip, radio frequency identification (RFID), near field communication (NFC), personal indentification number (PIN), integrated cash register (ICR), card verification value (CVV), 3D Secure, one time password (OTP), Contactless, Biometrik.

Teknologi chip merupakan alat yang ditanam dalam kartu kredit yang digunakan untuk menyimpan data pemilik kartu kredit. Teknologi chip menggantikan teknologi pita magnetik agar keamanan kartu kredit lebih terjamin. Chip hanya bisa dibaca dengan menggunakan alat electronic data capture (EDC). Teknologi chip lebih aman lagi jika disandingkan dengan penggunaan nomor identifikasi pribadi atau PIN.

Teknologi radio frequency identification (RFID) merupakan teknologi pengiriman informasi singkat lewat gelombang radio, dimana informasi disimpan dalam chip. Teknologi RFID terdapat dua jenis yaitu aktif dan pasif. RFID pasif yang lebih banyak digunakan pada kartu kredit. Chip RFID pasif tidak memiliki sumber daya sendiri dan baru akan aktif ketika ditempelkan atau didekatkan ke alat pembaca (RFID chip reader). Reader mengirimkan gelombang radio yang akan mengaktifkan chip RFID sekaligus membaca informasi yang tersimpan di dalamnya, sedangkan teknologi ini belum bisa menjamin keamanan data kartu kredit.

Teknologi near field communication (NFC) merupakan teknologi yang terapkan pada kartu kredit, dimana dalam melakukan transaksi, pemilik kartu tinggal menempelkan kartunya pada alat pembaca maupun smartphone. Teknologi ini kurang lebih sama cara kerjanya dengan teknologi RFID. Teknologi ini juga belum bisa menjamin keamanan data kartu kredit dalam melakukan transaksi.

Teknologi integrated cash register (ICR) atau mesin kasir terintegrasi merupakan mesin kasir yang langsung terhubung dengan mesin electronic data capture (EDC), dimana data yang terekam saat transaksi pembayaran non tunai dengan kartu hanya dapat dilakukan dengan nomor kartu yang bersangkutan, sehingga transaksi pembayaran lebih aman.

Teknologi card verification value (CVV) atau card verification code (CVC) merupakan fitur keamanan pembayaran elektronik dan online yang diterapkan oleh VISA dan Mastercard. Kode CVV/CVC ini terletak di tiga digit angka terakhir yang ada di belakang kartu kredit. Ketika melakukan transaksi online maka pemilik kartu kredit diarahkan untuk mengetikkan kode CVV/CVC sebagai verifikasi akhir pada saat transaksi menggunakan kartu kredit, sehingga transaksi lebih aman karena kode hanya pemilik kartu yang mengetahui.

Teknologi 3D Secure merupakan teknologi yang dikembangkan oleh VISA dan MasterCard demi menjaga keamanan transaksi online. Teknologi ini dikenal dengan Verified by Visa dan MasterCard Secure Code gunanya untuk memberikan kepastian bahwa setiap transaksi online benar-benar dilakukan hanya oleh sang pemilik kartu kredit. 3D Secure berbentuk sebuah kode yang muncul 
sebagai рор up di handphone pemilik kartu kredit waktu melakukan transaksi menggunakan kartu kredit secara online. Transaksi online dinyatakan berhasil jika pemilik kartu kredit sudah memasukkan kode $3 D$ Secure ke kotak input yang telah disediakan oleh situs tempat bertransaksi. Batas waktu yang diberikan bagi pemilik kartu kredit untuk mengisi $3 D$ Secure yaitu dengan rentang waktu 4 sampai 5 menit. Jika dalam batas waktu tersebut belum mengisi kode $3 D$ Secure maka transaksi dinyatakan gagal. Jadi teknologi ini bisa mengamankan transaksi online yang dilakukan pemilik kartu.

Teknologi one time password (OTP) merupakan teknologi password sekali pakai. Dengan teknologi ini sistem akan mengirimkan password khusus ke nomor telepon genggam pemilik kartu kredit yang sudah terdaftar di sistem Bank setiap kali melakukan transaksi online di merchant yang memiliki fasilitas ini, sehingga kartu kredit terproteksi dari potensi kejahatan online. Teknologi ini sama halnya dengan dengan teknologi 3D Secure, yang membedakannya hanya istilahnya saja.

Teknologi contactless merupakan teknologi nirsentuh dimana kartu kredit atau smartphone cukup didekatkan pada jarak 1.5-4 cm dari mesin pembaca kartu atau mesin contactless, maka transaksi pembayaran akan terjadi tanpa memerlukan PIN ataupun tanda tangan. Teknologi ini memasang antena yang ditanam disekeliling kartu yang berguna untuk melakukan transaksi secara nirsentuh atau menggunakan aplikasi kartu kredit pada smartphone. Cara kerja teknologi ini kurang lebih sama dengan RFID dan NFC, tetapi kartu kredit dengan teknologi contactless telah dijamin keamanannya dan telah disertifikasi oleh ISO Standard maupun Visa International dan MasterCard sebagai principal.

Teknologi biometrik adalah teknologi yang memungkinkan verifikasi pembayaran kartu kredit dengan menggunakan sidik jari, wajah atau suara. Jadi ketika melakukan transaksi maka dibutuhkan verifikasi biometrik dari pemilik kartu kredit berupa sidik jari atau wajah ataupun suara tergantung dari teknologi yang disediakan oleh bank penerbit kartu kredit. Data biometrik direkam sewaktu pengajuan pembuatan kartu kredit di bank penerbit kartu kredit. Teknologi ini dianggap paling aman dalam melakukan transaksi kartu kredit.

Dari beberapa teknologi keamanan kartu kredit yang telah dibahas, supaya kartu kredit mencapai tingkat keamanan yang maksimal maka diperlukan kombinasi teknologi keamanannya, sehingga faktor confidentiality, integrity dan availability dari kartu kredit bisa lebih terjaga.

\section{Jenis-Jenis Penipuan dan Kejahatan Kartu Kredit}

Penipuan kartu kredit memiliki dua tipe yaitu penipuan secara offline dan penipuan secara online (Chaudhary 2012). Bentuk penipuan dan kejahatan kartu kredit dapat berupa phising, skimming, carding, cracking, pencurian kartu kredit, ekstrapolasi, dan penipuan melalui telepon.

Phising merupakan suatu metode untuk melakukan penipuan dengan mengelabui target dengan maksud untuk mencuri data kartu kredit target secara online. Biasa pelaku kejahatan mengirim email ke calon korban dengan memalsukan situs bank penerbit kartu kredit, calon korban akan diminta untuk melakukan proses login ke alamat situs yang telah dipalsukan. Pada proses login calon korban akan diminta untuk mengisi data pribadi termasuk nomor kartu kredit. Kemudian data tersebut dijadikan oleh pelaku kejahatan untuk membobol kartu kredit. 
Skimming merupakan metode dilakukan oleh pelaku kejahatan untuk merekam data kartu kredit dengan menggunakan card skimmer. Card skimmer bisa membaca data kartu kredit yang menggunakan pita magnetik. Ukuran card skimmer sangat kecil sehingga memungkinkan pelaku untuk menyembunyikannya di mesin electronic data capture (EDC). Setelah terpasang di EDC, card skimmer akan merekam setiap data kartu kredit yang melakukan transaksi di mesin tersebut. Peretasan kartu kredit juga bisa terjadi melalui RFID dan NFC, ketika kartu kredit di dekatkan ke alat EDC atau pelaku kejahatan mendekati pemegang kartu maka dengan frekuensi tinggi di $13,56 \mathrm{MHz}$ dan menggunakan suatu alat "digital skimming" berteknologi sensor dengan jarak kurang lebih 15 sentimeter dapat merekam data dan informasi yang ada dalam kartu kredit. Data tersebut digunakan oleh pelaku kejahatan untuk melakukan transaksi secara online. Kemudian data tersebut juga bisa digunakan untuk menggandakan kartu kredit.

Carding adalah modus pelaku kejahatan untuk bertransaksi dengan menggunakan kartu kredit milik orang lain. Hal ini dimungkinkan karena pelaku kejahatan mengetahui nomor kartu kredit korban, sehingga dapat melakukan transaksi secara online.

Cracking merupakan modus pelaku kejahatan dengan cara membobol situs e-commerce, kemudian mengambil data nomor kartu kredit pelanggan yang bertransaksi di situs tersebut. Selain membobol situs, cracking juga sering menggunakan perangkat lunak sniffer. Perangkat lunak ini memanfaatkan celah transaksi kartu kredit melalui jaringan internet di area publik seperti di hotspot wifi dan warnet. Data kartu kredit digunakan oleh pelaku kejahatan untuk melakukan transaksi secara online.

Ekstrapolasi adalah modus kejahatan untuk memproduksi nomor kartu kredit secara tidak sah dengan cara mempelajari model algoritma pembuatan kartu kredit yang dilakukan oleh pihak bank penerbit. Biasanya, nomor kartu kredit terdiri dari 16 digit angka, setelah memproduksi nomor kartu kredit, pelaku kejahatan akan melakukan transaksi online di situs-situs $e$-commerce.

Pencurian kartu kredit merupakan tindak kejahatan offline dimana pelaku kejahatan mencuri kartu kredit milik orang lain, kemudian kartu kredit digunakan untuk bertransaksi dimana saja.

Penipuan melalui telepon merupakan modus kejahatan dimana pelakunya menggunakan nama perusahaan besar dan bank penerbit. Modusnya ada yang menawarkan promo suatu produk sampai korban tertarik dan menyerahkan data kartu kreditnya. Kemudian ada juga modus pelaku kejahatan menelpon korban dengan mengatasnamakan bank penerbit kemudian meminta kode OTP kepada korban yang telah dikirim oleh sistem kartu kredit dengan berbagai macam alasan sehingga korban terperdaya dan menyerahkan kode OTP kepada pelaku kejahatan. Setelah data atau kode OTP didapat oleh pelaku kejahatan maka digunakan dalam transaksi secara online.

\section{Pendeteksian Penipuan Kartu Kredit}

Dalam mendeteksi penipuan kartu kredit sudah banyak peneliti melakukan penelitian dengan berbagai macam algoritma, teknik dan strategi dalam penipuan kartu kredit pada transaksi offline dan online. Zaslavsky dan Anna (2006) melakukan penelitian mengenai pendeteksi penipuan kartu kredit menggunakan teknik self organizing maps. Patel dan Dheeraj (2013) melakukan penelitian 
mengenai pendeteksi dan pencegahan penipuan kartu kredit menggunakan algoritma genetika. Maes et al. (2015) melakukan penelitian mengenai pendeteksi penipuan kartu kredit menggunakan teknik bayesian dan jaringan saraf tiruan. Zareapoor dan Pourya (2015) melakukan penelitian mengenai penerapan deteksi penipuan kartu kredit berdasarkan pengelompokan "bagging ensemble". Jurgovsky et al. (2018) melakukan penelitian mengenai klasifikasi sequence untuk deteksi penipuan kartu kredit. Pozzolo et al. (2018) melakukan penelitian mengenai pendeteksi penipuan kartu kredit dengan pemodelan realistis dan strategi pembelajaran novel.

\section{Dampak Penipuan Kartu Kredit}

Jumlah kejadian tindak penipuan dan kejahatan kartu kredit menunjukkan kenaikan pada masyarakat. Aktivitas penipuan dan kejahatan pada kartu kredit memengaruhi dan berdampak kepada semua pihak terutama pemegang kartu kredit, merchant dan penerbit kartu kredit. Dampak penipuan kartu kredit sangat dirasakan bagi pemegang kartu, dimana mereka harus melaporkan transaksi yang mencurigakan ke pihak bank penerbit kartu, kemudian bank penerbit akan menyelidiki transaksi tersebut dengan pihak merchant, jika memang ada unsur penipuan maka pihak bank penerbit kartu akan memproses tagihan balik atau mengganti kerugian yang dialami pemegang kartu. Tetapi terdapat kasus penipuan kartu kredit dimana pelaku kejahatan sangat pintar sehingga transaksi yang dilakukannya seolah-olah seperti transaksi yang dilakukan oleh pemegang kartu padahal pemegang kartu tidak melakukan transaksi apapun, setelah ditelusuri oleh pihak bank penerbit kartu tidak ada unsur penipuan disana dan pihak bank tidak mau mengganti kerugian karena transaksi dianggap sah, sehingga pemegang kartu mengalami kerugian.

Penipuan kartu kredit juga berdampak bagi merchant dimana merchant tidak dapat membuktikan secara fisik misalnya bukti pengiriman bahwa transaksi yang telah terjadi karena pembayaran transaksi ditolak oleh pemegang kartu, oleh sebab itu merchant yang menanggung kerugian atas transaksi tersebut. Kerugian merchant meliputi harga pokok barang atau jasa, biaya pengiriman, biaya asosiasi kartu, biaya fee untuk bank, biaya administrasi dan kehilangan reputasi.

Kemudian penipuan kartu kredit juga berdampak bagi bank penerbit kartu kredit dimana ketika penipuan terjadi pihak pemegang kartu dan merchant menolak melakukan pembayaran maka pihak bank penerbit yang akan menanggung biaya transaksi, biaya administrasi dan biaya tenaga kerja. Kemudian pihak bank penerbit juga melakukan investasi besar dalam mencegah terjadinya penipuan dengan menerapkan sistem dan teknologi infromasi yang canggih untuk mendeteksi transaksi penipuan.

\section{Hubungan Perilaku Konsumen Terhadap Keamanan Kartu Kredit}

Pihak bank penerbit kartu kredit melakukan investasi yang besar dalam menjaga keamanan kartu kredit. Tidak hanya satu metode atau teknologi keamanan yang digunakan tapi menggunakan teknologi keamanan yang berlapis. Tetapi dengan adanya keamanan yang berlapis masih tetap bisa ditembus oleh para pelaku kejahatan kartu kredit. Ini bisa dilihat dimedia cetak, televisi dan online banyak memberitakan bahwa telah terjadi kasus kejahatan penipuan kartu kredit. Disini timbul pertanyaan, kenapa bisa terjadi kejahatan penipuan kartu 
kredit padahal pihak perbankan selaku penerbit kartu kredit telah memasang keamanan kartu kredit yang berlapis dan berteknologi canggih? Jawabannya akan terpulang kepada perilaku pemegang kartu kredit. Karena benteng atau lapisan keamanan terakhir kartu kredit adalah pribadi pemegang kartu kredit itu sendiri, sebab semua data dan informasi termasuk fisik kartu kredit dipunyai dan dipegang oleh pemegang kartu kredit. Tinggal bagaimana perilaku pemegang kartu kredit sebagai konsumen kartu kredit, apakah bisa melakukan tindakan menjaga kerahasiaan, kehati-hatian dan kewaspadaan dalam bertransaksi menggunakan kartu kredit. Menurut informasi dari pihak kepolisian dan berita dari media cetak, televisi dan online bahwa sebagian besar kasus kejahatan penipuan kartu kredit lebih banyak terjadi karena ketidaktahuan dan kelalaian dari konsumen sebagai pemegang kartu kredit.

\section{Solusi Keamanan Kartu Kredit}

Solusi dalam menjaga keamanan kartu kredit yaitu lebih difokuskan kepada pemegang kartu kredit karena pihak penerbit kartu kredit sudah melakukan tindakan pengamanan walaupun ada oknum dari pihak penerbit kartu kredit yang bermain untuk mendapatkan keuntungan dari konsumen. Yang harus dilakukan pemegang kartu kredit adalah menjaga kartu kredit ataupun aplikasi kartu kredit jangan sampai berpindah tangan atau diakses oleh orang lain baik itu orang terdekat. Ketika bertransaksi selalu perhatikan alat yang digunakan untuk membaca kartu kredit, pastikan aman dan asli. Jangan memberikan data dan informasi apapun mengenai kartu kredit kepada pihak lain. Jangan memberikan kode OTP kepada pihak manapun dan dengan alasan apapun. Jika bertransaksi online pastikan situs yang digunakan untuk kartu kredit adalah situs resmi atau asli. Jangan menggunakan koneksi jaringan umum atau publik untuk bertransaksi menggunakan kartu kredit.

\section{KESIMPULAN}

Perilaku konsumen dalam menggunakan kartu kredit secara dominan lebih dipengaruhi oleh faktor pribadi. Dengan adanya dorongan kebutuhan dan gaya hidup maka banyak konsumen tertarik menggunakan kartu kredit sebagai alat pembayaran dalam melakukan transaksi. Pihak perbankan selaku penerbit kartu kredit juga gencar dalam mempromosikan produk kartu kreditnya dengan menyediakan fitur keamanan yang canggih dan berlapis agar bisa menarik konsumen. Agar keamanan kartu kredit lebih aman dari kejahatan dan penipuan, maka perilaku konsumen harus dirubah dengan cara menjaga kerahasiaan, kehatihatian dan kewaspadaan dalam bertransaksi menggunakan kartu kredit, sehingga bisa meminimalisir terjadinya kejahatan dan penipuan kartu kredit.

\section{DAFTAR PUSTAKA}

Asosiasi Kartu Kredit Indonesia. 2020. Credit Card Growth. Diakses dari: https://www.akki.or.id/index.php/credit-card-growth, tanggal 13 Februari 2020 . 
Astari, Reny Widya. 2016. 5 Perbedaan Kartu Kredit Syariah dan Konvensional. Diakses dari: https://kreditgogo.com/artikel/Kartu-Kredit/5-PerbedaanKartu-Kredit-Syariah-dan-Konvensional.html, tanggal 13 Februari 2020.

Astuti, Niken Probondani dan Nurlaley Razak. 2017. "Analisis Perilaku Masyarakat Dalam Penggunaan Kartu Kredit Syariah Di Makassar". Jurnal Ilmiah AKSI 4 (4), 611-623.

Bank Indonesia. 2019. Credit Card Transactions. Diakses dari: https://www.bi.go.id/en/statistik/sistempembayaran/apmk/Documents/Transaksi\%20Kartu\%20Kredit\%20Tahun\% 20(en).docx, tanggal 12 Februari 2020.

Bank Indonesia. 2020. Edukasi Kartu Kredit. Diakses dari: https://www.bi.go.id/id/edukasi-perlindungan-konsumen/edukasi/produkdan-jasa-sp/kartu-kredit/Contents/Default.aspx, tanggal 13 Februari 2020.

Chaudhary, Khyati; Jyoti Yadav; Bhawna Mallick. 2012. "A review of Fraud Detection Techniques: Credit Card". International Journal of Computer Applications 45 (1), 39-44.

Dhirima, Silvia Anisa; Tuti Susilawati dan Mahipal. 2019. "Kajian Penerapan Prinsip Kehati-Hatian Dalam Penerbitan Kartu Kredit Pada Bank Syariah”. Jurnal Cendekia Ihya 2 (1), 30-42.

Engel, F. James; Roger D. Blackwell; Paul W. Miniard. 2004. Perilaku Konsumen (terjemahan). Jakarta: Binarupa Aksara.

Fauzan, Muhammad. 2017. "Gaya Hidup Nasabah dan Keputusan Penggunaan Kartu Kredit”. Esensi: Jurnal Bisnis dan Manajemen 7 (2), 181-192.

Firmansyah, M. Anang. 2018. Perilaku Konsumen (Sikap dan Pemasaran). Yogyakarta: Deep Publish.

Fitra, Safrezi. 2019. Perbankan dan Fintech Pembayaran, Bukan Lawan tapi Kawan. Diakses dari https://katadata.co.id/berita/2019/10/07/perbankandan-fintech-pembayaran-bukan-lawan-tapi-kawan, tanggal 12 November 2019.

Hendarsyah, Decky dan Retantyo Wardoyo. 2011. "Implementasi protokol diffiehellman dan algoritma RC4 untuk keamanan pesan SMS". IJCCS (Indonesian Journal of Computing and Cybernetics Systems) 5 (1), 14-25. https://doi.org/10.22146/ijccs.1997

Hendarsyah, Decky. 2012. "Keamanan Layanan Internet Banking Dalam Transaksi Perbankan”. IQTISHADUNA: Jurnal Ilmiah Ekonomi Kita 1 (1), 12-33.

Hendarsyah, Decky. 2015. "Keamanan Pertukaran Kunci Melalui SMS Menggunakan Modifikasi Protokol Diffie-Hellman". Jurnal Inovtek Polbeng 5 (1), 1-11.

Hendarsyah, Decky. 2016. "Penggunaan Uang Elektronik Dan Uang Virtual Sebagai Pengganti Uang Tunai Di Indonesia”. IQTISHADUNA: Jurnal Ilmiah Ekonomi Kita 5 (1), 1-15.

Hendarsyah, Decky. 2019. "E-Commerce Di Era Industri 4.0 dan Society 5.0". IQTISHADUNA: Jurnal Ilmiah Ekonomi Kita 8 (2), 171-185.

Ismail. 2018. "Minat Masyarakat Kota Banda Aceh terhadap Kartu Kredit Bank". Jurnal Ekonomi dan Manajemen Teknologi 2 (2), 89-98.

Jurgovsky, Johannes; Michael Granitzer; Konstantin Ziegler; Sylvie Calabretto; Pierre-Edouard Portier; Liyun He-Guelton and Olivier Caelen. 2018. 
"Sequence Classification for Credit-Card Fraud Detection". Expert Systems With Applications: An International Journal 100, 234-245.

Science Direct Elsevier. https://doi.org/10.1016/j.eswa.2018.01.037.

Kresna, Mawa. 2019. Bagaimana Data Nasabah Kartu Kredit Diperjualbelikan. Diakses dari: https://tirto.id/djSv, tanggal 12 Februari 2020.

Kristianti, Dewi Sukma. 2014. "Kartu Kredit Syariah Dan Perilaku Konsumtif Masyarakat". Ahkam: Jurnal Ilmu Syariah 14 (2), 287-296.

Lestari, Bunga Ayu; Budi Suharjo dan Istiqlaliyah Muflikhati. 2017. "Minat Kepemilikan Kartu Kredit (Studi Kasus Kota Bogor)". Jurnal Aplikasi Bisnis dan Manajemen 3 (1), 143-151.

Maes, Sam; Karl Tuyls; Bram Vanschoenwinkel and Bernard Manderick. 2015. "Credit Card Fraud Detection Using Bayesian and Neural Networks". Research Gate.

Margaretha, Farah dan Siti May Sari. 2015. "Faktor Penentu Tingkat Literasi Keuangan Para Pengguna Kartu Kredit di Indonesia". Journal of Accounting and Investment 16 (2), 132-144.

Miftahuddin and Decky Hendarsyah. 2019. "Analisis Perbandingan Fasilitas Aplikasi Mobile Banking Bank Syariah Mandiri KCP. Bengkalis Dengan Bank Mandiri KC. Bengkalis". IQTISHADUNA: Jurnal Ilmiah Ekonomi Kita 8 (1), 16-32.

Mowen, Jhon C. and Michael Minor. 1998. Consumer Behavior 6ed. New Jersey: Prentice Hall.

Patel, Rinky D. and Dheeraj Kumar Singh. 2013. "Credit Card Fraud Detection \& Prevention of Fraud Using Genetic Algorithm". International Journal of Soft Computing and Engineering (IJSCE) 2 (6), 292-294.

Pozzolo, Andrea Dal; Giacomo Boracchi; Olivier Caelen; Cesare Alippi and Gianluca Bontempi. 2018. "Credit Card Fraud Detection: A Realistic Modeling and a Novel Learning Strategy". IEEE Transactions On Neural Networks And Learning Systems 29 (8), 3784-3797.

Prisgunanto, Ilham. 2017. "Identifikasi Pemilihan Konsumen Kartu Kredit Di Indonesia". CoverAge: Journal of Strategic Communication 7 (2), 29-39.

Setiadi, Nugroho J. 2013. Perilaku Konsumen, Edisi Revisi. Jakarta: Kencana.

Simamora, Bilson. 2004. Panduan Riset perilaku Konsumen, edisi kedua. Jakarta: PT. Gramedia Pustaka Utama.

Tokopedia. 2019. 10 Manfaat Kartu Kredit yang Memudahkan Urusan Finansial. Diakses dari: https://www.tokopedia.com/blog/fin-manfaat-kartu-kreditkeuntungan/, tanggal 13 Februari 2020.

Yusuf, Zainul Arifin. 2011. "Perbandingan Kartu Kredit Dan Kartu Kredit Berbasis Syariah Di Indonesia”. Al-Iqtishad: Jurnal Ilmu Ekonomi Syariah 3 (2), 255-272.

Zareapoor, Masoumeh and Pourya Shamsolmoali. 2015. "Application of Credit Card Fraud Detection: Based on Bagging Ensemble Classifier". Procedia Computer Science 48, 679-685. Science Direct Elsevier.

Zaslavsky, Vladimir and Anna Strizhak. 2006. "Credit Card Fraud Detection Using Self-Organizing Maps". Information \& Security: An International Journal 18, 48-63.

Zuhra, Wan Ulfa Nur. 2017. Untung Rugi Pakai Kartu Kredit Syariah. Diakses dari: https://tirto.id/csjB, tanggal 13 Februari 2020. 